\title{
AC Recombination Velocity in the Back Surface of a Lamella Silicon Solar Cell under Temperature
}

\author{
Youssou Traore1, Ndeye Thiam², Moustapha Thiame3, Amary Thiam1, Mamadou Lamine Ba², \\ Marcel Sitor Diouf', Ibrahima Diatta1, Oulymata Mballo', El Hadji Sow ${ }^{1}$, Mamadou Wade², \\ Grégoire Sissoko ${ }^{1}$
}

\author{
${ }^{1}$ Laboratory of Semiconductors and Solar Energy, Physics Department, Faculty of Science and Technology, University Cheikh \\ Anta Diop, Dakar, Senegal \\ ${ }^{2}$ Laboratory of Sciences and Techniques of Water and Environment, Polytechnic School of Thiès, Thiès, Senegal \\ ${ }^{3}$ University Assane SECK, Ziguinchor, Senegal \\ Email: gsissoko@yahoo.com
}

How to cite this paper: Traore, Y., Thiam, N., Thiame, M., Thiam, A., Ba, M.L., Diouf, M.S., Diatta, I., Mballo, O., Sow, E.H., Wade, M. and Sissoko, G. (2019) AC Recombination Velocity in the Back Surface of a Lamella Silicon Solar Cell under Temperature. Journal of Modern Physics, 10, 12351246.

https://doi.org/10.4236/jmp.2019.1010082

Received: August 26, 2019

Accepted: September 20, 2019

Published: September 23, 2019

Copyright (c) 2019 by author(s) and Scientific Research Publishing Inc. This work is licensed under the Creative Commons Attribution International License (CC BY 4.0).

http://creativecommons.org/licenses/by/4.0/

\begin{abstract}
The ac recombination velocity of the excess minority carriers, in the back surface of a silicon solar cell with a vertical junction connected in series, is developed through Einstein's law giving the diffusion coefficient of minority carriers according to temperature, through mobility. The frequency spectrum of both, amplitude and phase, are produced for the diffusion coefficient and the recombination velocity in the rear face, in order to identify the parameters of equivalent electric models.
\end{abstract}

\section{Keywords}

Vertical Multi-Junctions, Solar Cell, AC Back Surface Recombination Velocity, Temperature, Bode and Nyquist Diagrams

\section{Introduction}

Vertical multi-junctions (VMJ) silicon solar cells have an architecture that is an alternative for collecting minority carriers with low-diffusion length [1] [2] [3] [4] [5].

Two types of VMJ solar cells are developed, by a succession of npp or pnn junctions. The VMJ-P has connections in parallel, between bases and connections between emitters. Thus a base type (p) is surrounded by two emitters allowing the collection of minority carriers at close range, leading to the increase 
of photocurrent [6] [7] [8]. The VMJ-S, presents a succession of npp+ or pnn+ solar cells, connected in series, allowing increasing the electrical voltage [9].

The VMJ is designed to operate under light concentration to generate more minority carriers, thereby increasing voltage or current production. In this situation, temperature is an important factor that influences the operating performance of the solar cell, through the physical mechanisms that are important to study [10]. In this work, the ac recombination velocity in the rear face $(\mathrm{p} / \mathrm{p}+)$ of the solar cell, is determined and studied in temperature using the frequency spectrum of its amplitude and phase.

\section{Theory}

The structure of the serially connected vertical multi-junctions silicon solar cell, under monochromatic illumination in frequency modulation, is given by Figure $1[11]$.

The unit of the solar cell extracted from the series representation, is a npp+ structure, the base of which is studied by variation in the temperature $T$ (Figure 2).

The continuity equation relating to the excess minority carriers density $\delta(x, z, T, t)$ in the base at temperature $T$, and under monochromatic illumination in frequency modulation, is given by the relationship [12] [13]:

$$
D(\omega, T) \times \frac{\partial^{2} \delta(x, z, \omega, T, t)}{\partial x^{2}}-\frac{\delta(x, z, \omega, T, t)}{\tau}=-G(z, \omega, t)+\frac{\partial \delta(x, z, \omega, T, t)}{\partial t}
$$

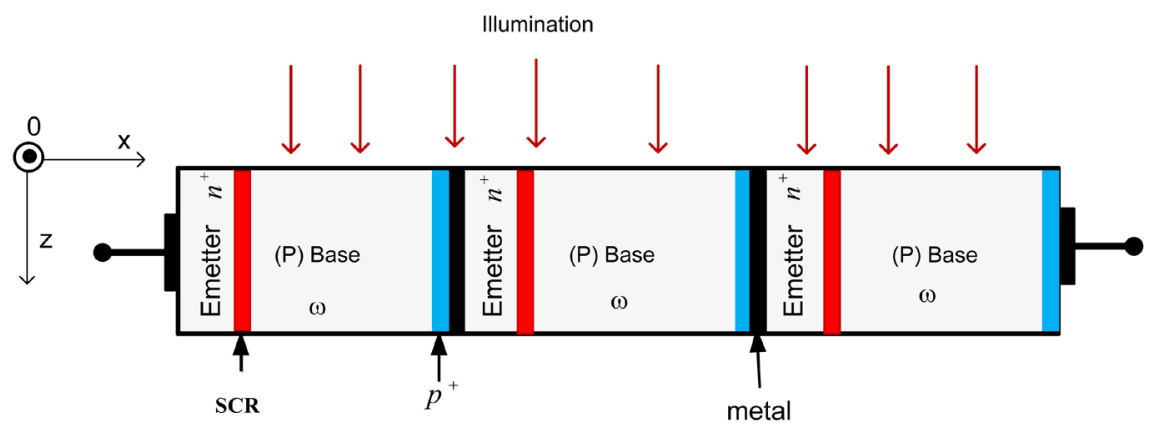

Figure 1. Schematic of a series-connected vertical multi-junction solar cells.

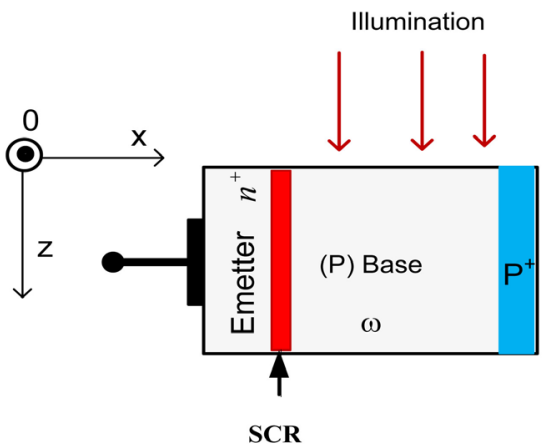

Figure 2. Across section of the vertical junction. 
The density of photogenerated carriers is written according to the space coordinates $(x, z)$ and the time $t$ as:

$$
\delta(x, z, t)=\delta(x, z) \exp (-j \omega t)
$$

The minority carriers generation rate at depth $z$ in the base and at any point of absciss $x$, under the modulation frequency $\omega$ of the incident wave, is given by the relationship:

$$
G(z, \omega, t)=g(z) \exp (-j \omega t)
$$

where $g(z)$ is the steady stateminority carriers generation rate at the $z$ depth induced in the base by a monochromatic light of incident flow $\phi(\lambda)$, respectively with monochromatic absorption and reflecting coefficients $\alpha(\lambda)$ and $R(\lambda)$. It is then written by the following relation:

$$
g(z)=\alpha(\lambda) \cdot(1-R(\lambda)) \cdot \phi(\lambda) \cdot \exp (-\alpha(\lambda) \cdot z)
$$

With $\tau$ the excess minority carrier lifetime in the base.

$D(\omega, T)$ is the complex diffusion coefficient of excess minority carrier in the base at T-temperature. Its expression is given by the relationship [14]:

$$
D(\omega, T)=\frac{D(T)\left(1-j \cdot \omega^{2} \tau^{2}\right)}{1+(\omega \tau)^{2}}
$$

$D_{0}(T)$ is the temperature-dependent diffusion coefficient given by Einstein's relationship [15]:

$$
D(T)=\mu(T) \cdot \frac{K_{b} \cdot T}{q}
$$

$T$ is the temperature in Kelvin, $K_{b}$ the Boltzmann constant:

$$
K_{b}=1.38 \times 10^{-23} \mathrm{~m}^{2} \cdot \mathrm{kg} \cdot \mathrm{S}^{-2} \cdot \mathrm{K}^{-1}
$$

The minority carrier mobility coefficient [16] expressed according to the temperature, is given by:

$$
\mu(T)=1.43 \times 10^{9} T^{-2.42} \mathrm{~cm}^{2} \cdot \mathrm{V}^{-1} \cdot \mathrm{s}^{-1}
$$

By replacing the Equations (2) and (3) in the Equation (1), the continuity equation for the excess minority carriers density in the base is reduced to the following relationship:

$$
\frac{\partial^{2} \delta(x, z, \omega, T)}{\partial x^{2}}-\frac{\delta(x, z, \omega, T)}{L^{2}(\omega, T)}=-\frac{G(x, z)}{D(\omega, T)}
$$

$L(\omega, T)$ is the complex diffusion length of excess minority carrier in the base; ilest donné par :

$$
L(\omega, T)=\frac{\sqrt{D(\omega, T) \tau}}{\sqrt{1+j \cdot \omega \cdot \tau}}
$$

$(\omega, T)$ is the ac minority carriers diffusion coefficient in the base under the influence of temperature and the minority carrier lifetime in the base. 
Thus the solution of the Equation (9) is given by the following expression of the ac density of minority carriers:

$$
\begin{aligned}
\delta(x, \omega, T, z)= & A \cosh \left(\frac{x}{L(\omega, T)}\right)+B \sinh \left(\frac{x}{L(\omega, T)}\right) \\
& +\frac{L^{2}(\omega, T)}{D(\omega, T)} \cdot \alpha_{t}(1-R(\lambda)) \cdot \phi(\lambda) \cdot \exp \left(\alpha_{t} \cdot z\right)
\end{aligned}
$$

Coefficients $A$ and $B$ are determined from conditions at the base space boundaries, i.e. at the junction $(x=0)$ and in the rear $(x=H)$ and are expressed by:

1) At, $x=0$, at the junction emitter-base (n/p) surface

$$
\left.D(\omega, T) \cdot \frac{\partial \delta(x, z, T, \omega)}{\partial x}\right|_{x=0}=\left.S f \cdot \delta(x, z, T, \omega)\right|_{x=0}
$$

2) At, $x=H$, the back surface $(\mathrm{p} / \mathrm{p}+)$

$$
\left.D(\omega, T) \cdot \frac{\partial \delta(x, z, \omega)}{\partial x}\right|_{x=H}=-\left.S b \cdot \delta(x, z, T, \omega)\right|_{x=H}
$$

where $S f$ is the junction surface recombination velocity [17]. It can be represented into the sum of two terms. We then get:

$$
S f=S f_{O}+S f_{j}
$$

$S f_{O}$, defines the lost electrical charges velocity at the junction surface and is related to shunt resistance in establishing the electric model equivalent to the illuminated solar cell [17] [18].

$S f_{j}$ is the velocity of the flow of electrical charges that crosses through the external charge and defines the solar cell operating point [18].

$\mathrm{Sb}$ is the excess minority carrier recombination velocity at the rear surface of the solar cell's base $(\mathrm{p} / \mathrm{p}+)$ [19]. It characterizes the electric field in this area (low-high junction), which allows the return of minority carrier to the junction to participate in the photocurrent.

\section{Results and Discussions}

\subsection{Diffusion Coefficient: Bode and Nyquist Diagrams for Différent Temperatures}

The amplitude and phase of the diffusion coefficient under different temperatures, are represented versus frequency, through the Figure 3 and Figure 4.

For a given temperature, the diffusion coefficient is maximum and virtually constant when the frequency is low. Indeed, in a quasi-static regime the diffusion of minority carriers is not influenced by the frequency which explains the level observed. On the other hand, in a dynamic frequency regime, repeated arousals lead to a problem of relaxation of the solar cell which is a blocking factor for the diffusion of minority carriers. In addition, an increase in temperature decreases the diffusion of minority carriers. The diffusion is more sensitive to temperature in a quasi-static regime. 


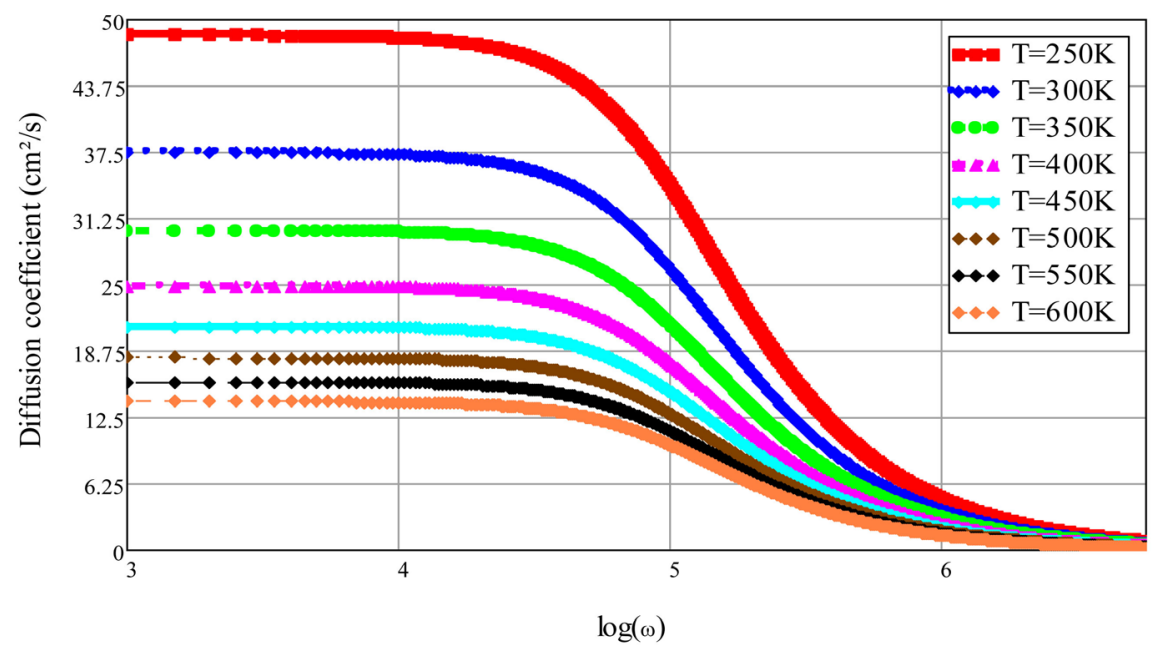

Figure 3. Diffusion coefficient versus frequency for different temperatures.

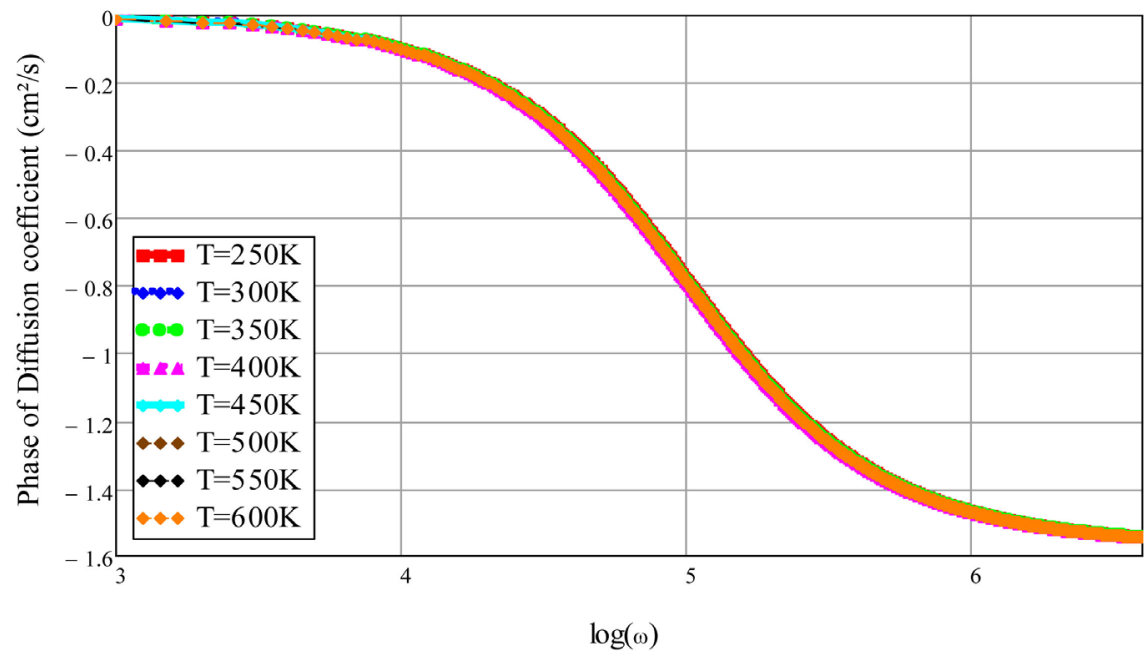

Figure 4. Diffusion coefficient phase versus frequency for different temperatures.

In a dynamic frequency regime, the problem of relaxation in the solar cell, blocks the diffusion of the minority carriers which gives a negative phase of the diffusion coefficient. The Nyquist diagram is shown in Figure 5.

We find that the radius of the semicircles decreases according to the temperature with a shift from the center of the circles to the origin of the axes. The semicircle indicates a resistor in parallel with a capacitor, so gives rise to a single time constant. The deformation of the semicircles, corresponds to a time constant, time dependent. The exploitation of the half-circle radius allows to determine electrical parameters characteristic of the equivalent electric model.

\subsection{Photocurrent}

The density of photocurrent at the junction is obtained from the density of minority carriers in the base and is given by the following expression: 


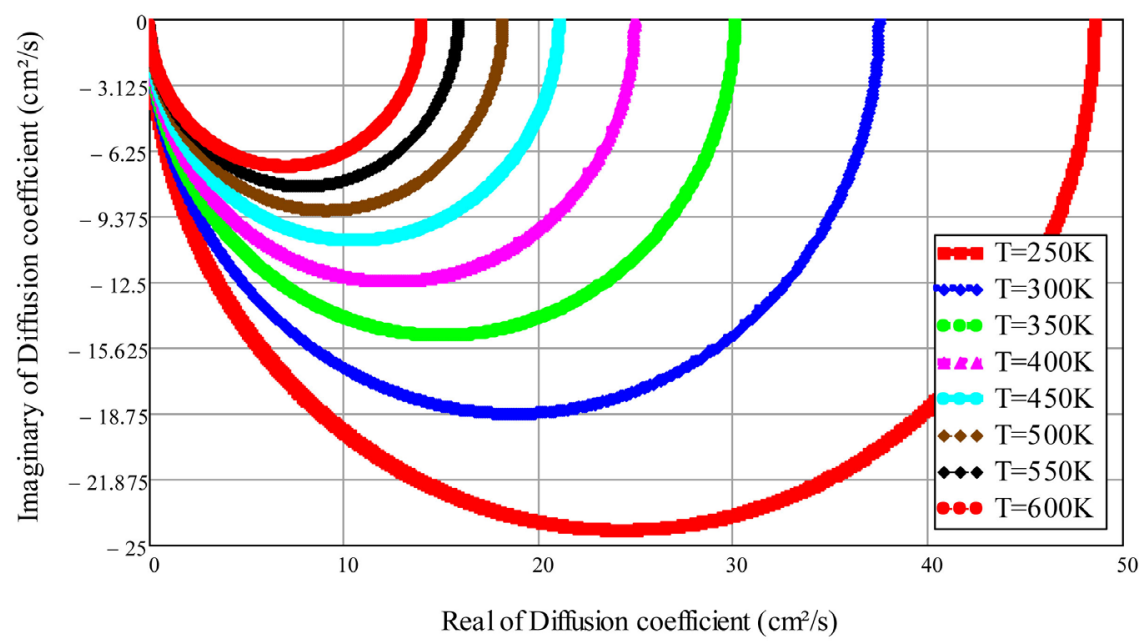

Figure 5. Imaginary component versus real component of diffusion coefficient for different temperatures.

$$
J_{P h}(\omega, T, S f, S b)=\left.q \cdot D(\omega, T) \cdot \frac{\partial \delta(x, \omega, T, S f, S b)}{\partial x}\right|_{x=0}
$$

where $q$ is the elementary electron charge.

Figure 6 shows ac photocurrent density versus the junction surface recombination velocity for different temperatures.

\subsection{Deduction of the $S b(\omega, T)$ Expression}

The representation of photocurrent density according to the junction recombination velocity of minority carriers shows that, for very large $S f$, a bearing sets up and corresponds to the short-circuit current density (Jphsc). So in this junction recombination velocity interval, we can write [20]:

$$
\frac{\partial J_{p h}(\omega, T, S f, S b)}{\partial S f}=0
$$

The solution of this equation leads to expressions of the ac recombination velocity in the back surface, given by:

$$
\begin{gathered}
\operatorname{Sbl}(\omega, T)=\frac{D(\omega, T) \cdot \sinh \left(\frac{H}{L(\omega, T)}\right)}{L(\omega, T) \cdot\left[\cosh \left(\frac{H}{L(\omega, T)}\right)-1\right]} \\
\operatorname{Sb} 2(\omega, T)=-\frac{D(\omega, T)}{L(\omega, T)} \cdot \tanh \left(\frac{H}{L(\omega, T)}\right)
\end{gathered}
$$

Previous studies have looked at the second solution given to the Equation (18). Our study will consider this second solution, whose module and phase are represented versus the logarithm of the modulation frequency by the Figure 7 and Figure 8, for different temperatures. 


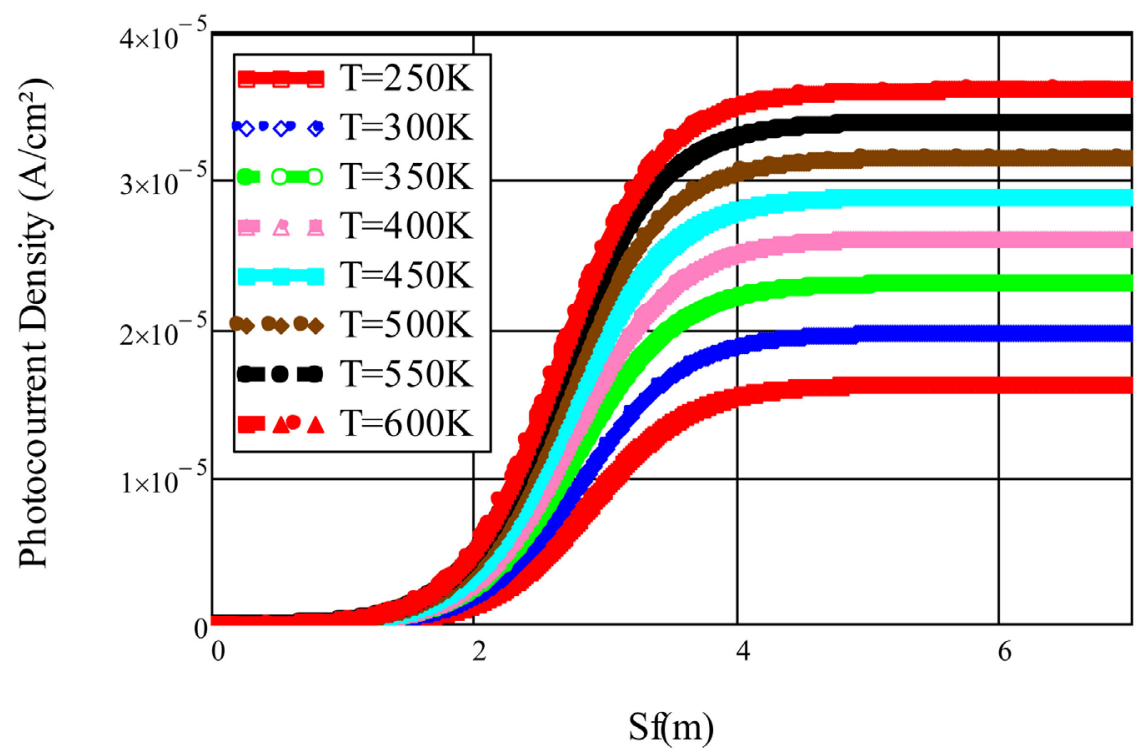

Figure 6. Photocurrent density versus junction surface recombination velocity under temperature influence. $\omega=10^{5} \mathrm{rad} / \mathrm{s}, H=0.025 \mathrm{~cm} ; z=0.017 \mathrm{~cm} ; \lambda=0.9$ $\mu \mathrm{m}$.

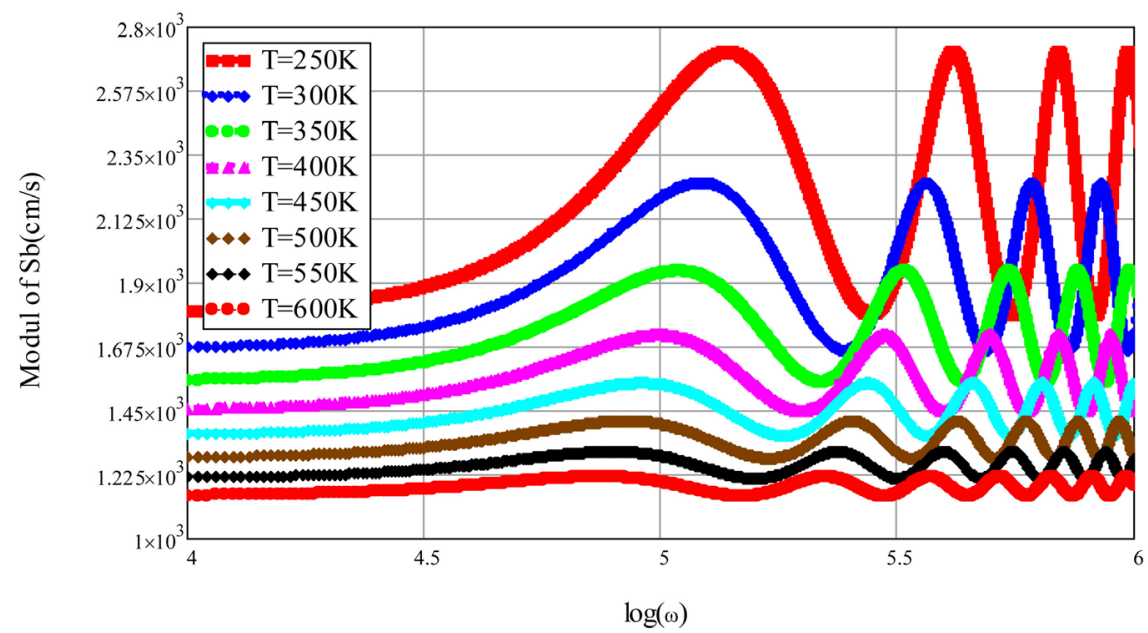

Figure 7. Module of Sb versus frequency for different temperatures.

Ac Sb in complex form (real and imaginary components) is presented by analogy of the effect of Maxwell-Wagner-Sillars (MWS) model [21] [22] [23] and can be written as:

$$
S b(\omega, T)=S b^{\prime}(\omega, T)+J \cdot S b^{\prime \prime}(\omega, T)
$$

We define the ac phase for a given temperature, as following equation:

$$
\tan (\phi(\omega, T))=\frac{S b^{\prime \prime}(\omega, T)}{S b^{\prime}(\omega, T)}
$$

$S b_{\text {ampl }}(\omega, T)$ and $\phi(\omega, T)$ correspond for a given temperature $T$, to the amplitude and phase component of $\boldsymbol{S b}$. 
At low frequencies $\left(\leq 10^{4} \mathrm{rad} / \mathrm{s}\right)$, the stationary regime is observed and gives constant amplitudes for each $\mathrm{T}$. These amplitudes decrease with the temperature $T$. Beyond the frequency ( $\gg 10^{4} \mathrm{rad} / \mathrm{s}$ ), the cut-off frequency $\left(\omega_{c}, s b(T)\right.$ ) is determined for each temperature. It is noted that the cut-off frequency decreases with the temperature $T$, as does the amplitude $\left(S b_{\text {ampl }}\right)$ and on the other hand the frequency $\left(\omega_{S b}(T)\right)$ of oscillations increases, in the part corresponding to the dynamic regime(See Table 1 ).

The phase is represented versus the logarithm of the modulation frequency. The part corresponding to the dynamic regime shows sinusoidal oscillations between positive and negative values of the phase, amplitude ( $\Phi$ ampl) that decreases with the temperature $T$ and the frequency of oscillations $\left(\omega_{\Phi}\right)$, which on the other hand increases with the temperature $T$ (See Table 2).

Figure 9 produces the Niquyst diagram of the excess minority carrier recombination velocity for different temperatures. The radius of the resulting circles decreases with temperature, with a shift from the center of the circles to the origin of the axes (See Table 3 and Table 4).

Figure 10 and Figure 11 show that the sb recombination velocity decreases with temperature. Indeed, when the temperature is above the optimum temperature (Topt-300 K) [24], thermal agitation leads to the exponential evolution of umklapp processes that predict a temperature dependence of thermal conductivity

Table 1. Ac Sb periods for different temperatures.

\begin{tabular}{ccccccccc}
\hline$T(\mathrm{~K})$ & 250 & 300 & 350 & 400 & 450 & 500 & 550 & 600 \\
\hline$\omega_{c}(\mathrm{rad} / \mathrm{s})$ & $10^{4.34}$ & $10^{4.38}$ & $10^{4.33}$ & $10^{4.24}$ & $10^{4.23}$ & $10^{4.24}$ & $10^{4.06}$ & $10^{4.18}$ \\
$S b(T)(\mathrm{cm} / \mathrm{s})$ & 1837.1 & 1813.1 & 1583.9 & 1523.8 & 1377 & 1295.5 & 1240 & 1156.3 \\
$S b, \mathrm{ampl}(\mathrm{cm} / \mathrm{s})$ & 2711.3 & 2118.7 & 1940.9 & 1650.4 & 1547.4 & 1414.5 & 1280.5 & 1218.6 \\
$\omega(\mathrm{rad} / \mathrm{s})$ & $10^{5.14}$ & $10^{5.00}$ & $10^{5.04}$ & $10^{4.91}$ & $10^{4.96}$ & $10^{4.93}$ & $10^{4.82}$ & $10^{4.87}$ \\
\hline
\end{tabular}

Table 2. Ac Sb, phase period for different temperatures.

\begin{tabular}{ccccccccc}
\hline$T(\mathrm{~K})$ & 250 & 300 & 350 & 400 & 450 & 500 & 550 & 600 \\
\hline$\Phi \mathrm{ampl}$ & 0.20 & 0.15 & 0.11 & 0.08 & 0.06 & 0.04 & 0.03 & 0.02 \\
$\omega_{\Phi}(\mathrm{rad} / \mathrm{s})$ & $10^{4.85}$ & $10^{4.79}$ & $10^{4.74}$ & $10^{4.70}$ & $10^{4.67}$ & $10^{4.64}$ & $10^{4.61}$ & $10^{4.57}$
\end{tabular}

Table 3. Maximum amplitude of the imaginary part of $\mathrm{Sb}$ for different temperatures.

\begin{tabular}{ccccccccc}
\hline$T(\mathrm{~K})$ & 250 & 300 & 350 & 400 & 450 & 500 & 550 & 600 \\
\hline $\mathrm{ImSb}_{\max }(\mathrm{cm} / \mathrm{s})$ & 459.96 & 293.63 & 195.11 & 132.75 & 92.77 & 65.36 & 47.41 & 34.63 \\
\hline
\end{tabular}

Table 4. Parallel resistors characterizing Sb for different temperatures.

\begin{tabular}{ccccccccc}
\hline$T(\mathrm{~K})$ & 250 & 300 & 350 & 400 & 450 & 500 & 550 & 600 \\
\hline $\operatorname{Re}(S b(\mathrm{~cm} / \mathrm{s}))$ & 2712 & 2252 & 1941 & 1717 & 1547 & 1415 & 1307 & 1219 \\
$\frac{1}{\operatorname{Re}(S b(\mathrm{~cm} / \mathrm{s})) \cdot 10^{-5}}$ & 36.873 & 44.405 & 51.52 & 58.241 & 64.641 & 70.671 & 76.511 & 82.034
\end{tabular}




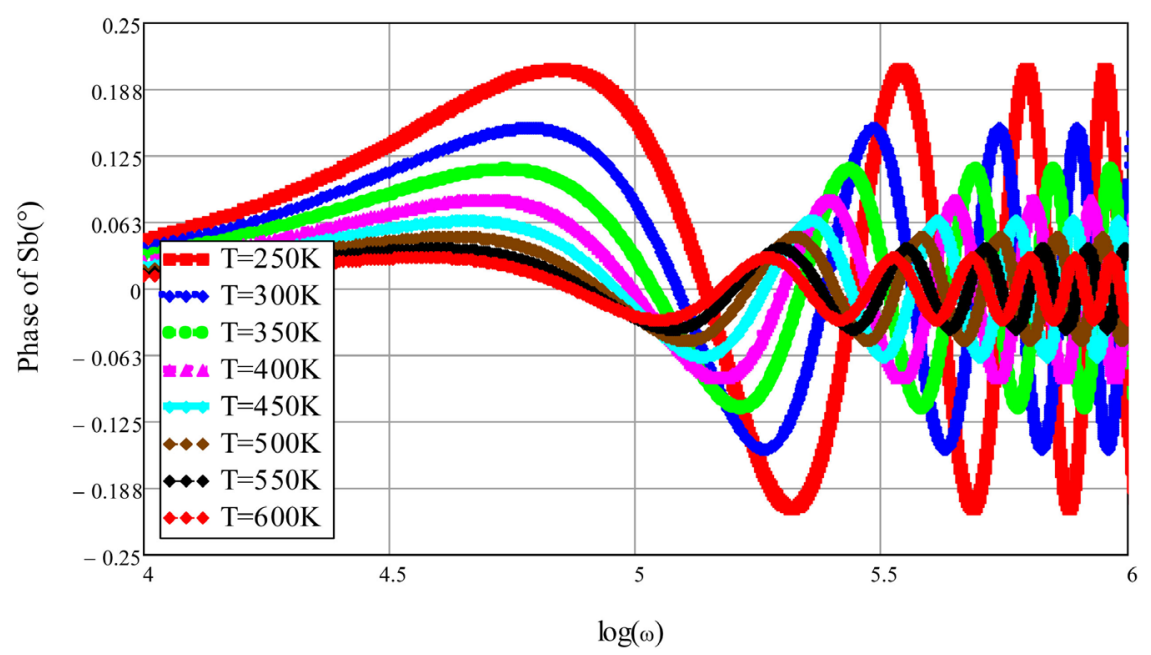

Figure 8. Phase of Sb versus frequency for different temperatures.

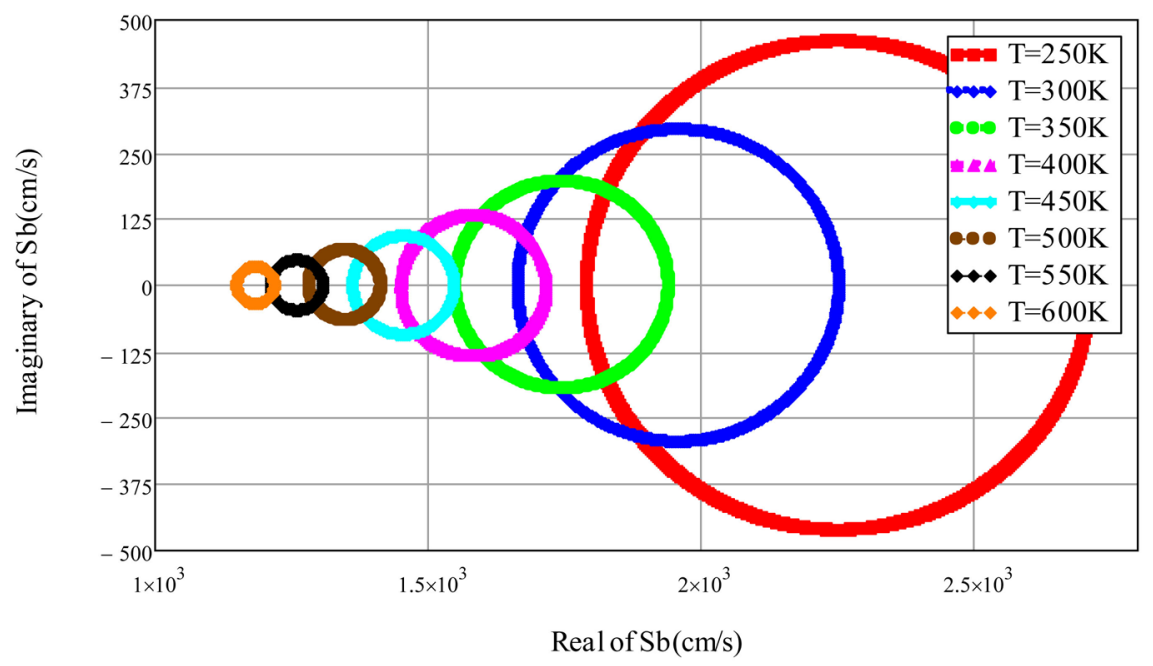

Figure 9. Imaginary compoment versus real compoment of $\mathrm{Sb}$ for different Temperatures.

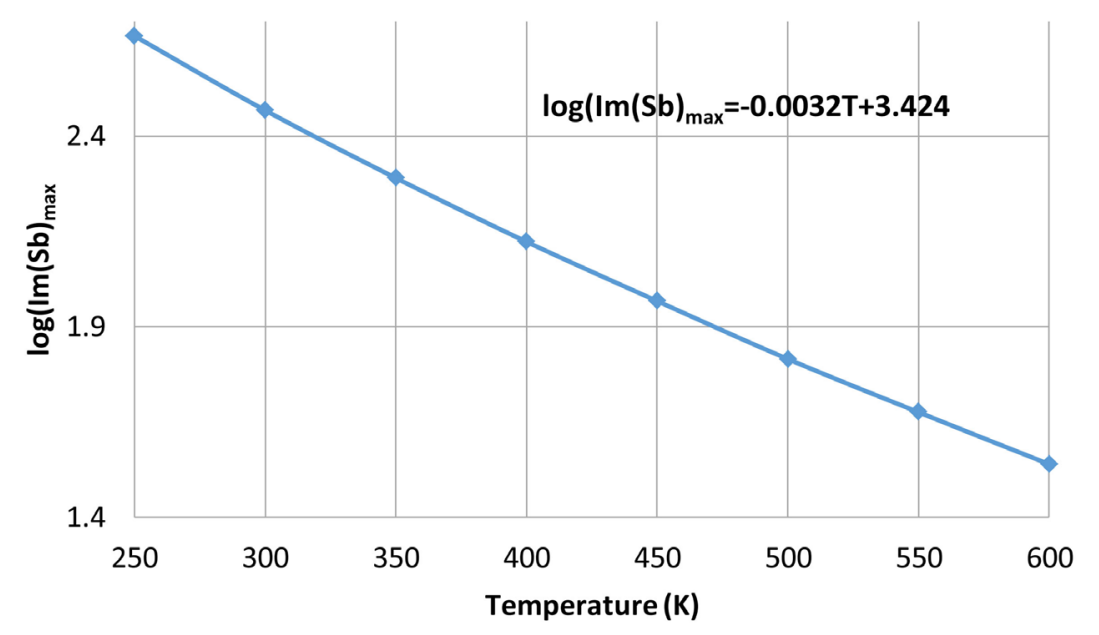

Figure 10. $\log (\operatorname{Im}(\mathrm{Sb}))$ versus of temperature. 


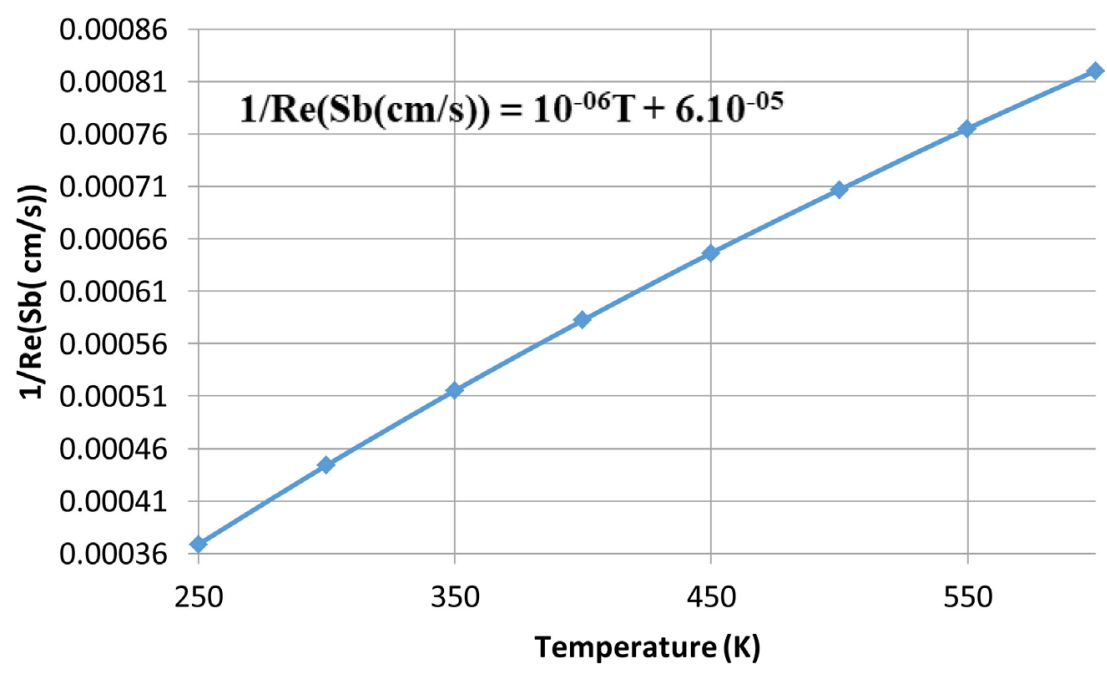

Figure 11. Reciprocal of Sb real part versus temperature.

in $1 / T$ [25] [26] [27]. This decreases the mobility of excess minority carriers and results in a decrease in the diffusion coefficient [25] which increases recombination.

The negative phase of the ac $\mathrm{Sb}$ recombination velocity and the determination of electrical parameters, with the Bode and Nyquist diagrams, characterizing $\mathrm{Sb}$, allow to determine the equivalent electric model [28] [29].

\section{Conclusion}

The solar cell's ac back surface $(\mathrm{p} / \mathrm{p}+)$ recombination velocity that controls the recombination of the excess minority carrier has been determined. Thus, the spectroscopy method allowed the study of the Bode and Nyquist diagrams and extracted certain electrical parameters characterizing the equivalent electric model. The effect of temperature on back surface recombination velocity was explained by umklapp processes.

\section{Conflicts of Interest}

The authors declare no conflicts of interest regarding the publication of this paper.

\section{References}

[1] Nam, L.Q., et al. (1992) International Journal of Solar Energy, 11, 273-279. https://doi.org/10.1080/01425919208909745

[2] Yadav, P., Pandey, K., Tripathi, B., Kumar, C.M., Srivastava, S.K., Singh, P.K. and Kumar, M. (2015) Solar Energy, 122, 1-10. https://doi.org/10.1016/j.solener.2015.08.005

[3] Wise, J.F. (1970) Vertical Junction Hardened Solar Cell. U.S. Patent 3, 690-953.

[4] Gover, A. and Stella, P. (1974) IEEE Transactions on Electron Devices, 21, 351-356. https://doi.org/10.1109/T-ED.1974.17927

[5] Mazhari, B. and Morkoç, H. (1993) Journal of Physics A, 73, 7509-7514. 
https://doi.org/10.1063/1.353998

[6] Gueye, M., Diallo, H.L., Moustapha, A.M., Traore, Y., Diatta, I. and Sissoko, G. (2018) World Journal of Condensed Matter Physics, 8, 185-196.

http://www.scirp.org/journal/wjcmp https://doi.org/10.4236/wjcmp.2018.84013

[7] Ngom, M.I., Thiam, A., Sahin, G., El Moujtaba, M.A.O., Faye, K., Diouf, M.S. and Sissoko, G. (2015) International Journal of Pure \& Applied Sciences \& Technology, 31, 65-75.

[8] Diallo, H.L., Dieng, B., Ly, I., Dione, M.M., Ndiaye, M., Lemrabott, O.H., Bako, Z.N., Wereme, A. and Sissoko, G. (2012) Research Journal of Applied Sciences, Engineering and Technology, 4, 2626-2631.

[9] Terheiden, B., Hahn, G., Fath, P. and Bucher, E. (2000) The Lamella Silicon Solar Cell. 16th European Photovoltaic Solar Energy Conference, Glasgow, 1-5 May 2000, 1377-1380.

[10] Dieme, N., Zoungrana, M., Mbodji, S., Diallo, H.L., Ndiaye, M., Barro, F.I. and Sissoko, G. (2014) Research Journal of Applied Sciences, Engineering and Technology, 7, 2559-2562. https://doi.org/10.19026/rjaset.7.567

[11] Xing, Y., Han, P., Wang, S., Liang, P., Lou, S., Zhang, Y., Hu, S., Zhu, H., Mi, Y. and Zhao, C. (2013) Science China Technological Sciences, 56, 2798-2807. https://doi.org/10.1007/s11431-013-5378-Z

[12] Heinbockel, J.H. and Walker, G.H. (1988) Three-Dimensional Models of Conventional and Vertical Junction Laser-Photovoltaic Energy Converters. NASA-TM403919880014727.

[13] Sarfaty, R., Cherkun, A., Pozner, R., Segev, G., Zeierman, E., Flitsanov, Y., Kribus, A. and Rosenwaks, Y. (2011) Vertical Junction Si Micro-Cells for Concentrating Photovoltaics. Proceedings of the 26 th European Photovoltaic Solar Energy Conference and Exhibition, Hamburg, 5-6 September 2011, 145-147.

[14] Sze, S.M. (1981) Physics of Semiconductor Devices. John Wiley \& Sons, Hoboken.

[15] Mohammad, S.N. (1987) Journal of Applied Physics, 61, 767-772. https://doi.org/10.1063/1.338230

[16] Kunst, M. and Sanders, A. (1992) Semiconductor Science and Technology, 7, 51-59. https://doi.org/10.1088/0268-1242/7/1/009

[17] Sissoko, G., Museruka, C., Corréa, A., Gaye, I. and Ndiaye, A.L. (1996) Renewable Energy, 3, 1487-1490.

[18] Sissoko, G., Nanéma, E., Corréa, A., Biteye, P.M., Adj, M. and Ndiaye, A.L. (1996) Renewable Energy, 3, 1848-1851.

[19] Bocande, Y.L., Corréa, A., Gaye, I., Sow, M.L. and Sissoko, G. (1994) Bulk and Surfaces Parameters Determination in High Efficiency Si Solar Cells. Proceedings of the World Renewable Energy Congress, Vol. 3, 1698-1700.

[20] Stamboulis, A., Baillie, C.A. and Peijs, T. (2001) Composites Part A, 32, 1105-1115. https://doi.org/10.1016/S1359-835X(01)00032-X

[21] Maxwell, J.C. (1982) Electricity and Magnetism. Calerdon, Oxford, 1.

[22] Lestriez, B. and Maazouz, A. (1998) Polymer, 39, 6733-6742. https://doi.org/10.1016/S0032-3861(98)00093-7

[23] Bottcher, C.J.F. and Bordewijik, P. (1979) Advances in Molecular Relaxation and Interaction Processes, 14, 161-162. https://doi.org/10.1016/0378-4487(79)80023-0

[24] Mane, R., Ly, I., Wade, M., Datta, I., Douf, M.S., Traore, Y., Ndiaye, M., Tamba, S. 
and Sissoko, G. (2017) Energy and Power Engineering, 9, 1-10.

https://doi.org/10.4236/epe.2017.91001

[25] Berman, R. (1951) Nature, 168, 277-280. https://doi.org/10.1038/168277a0

[26] Casimir, H.B.G. (1938) Physica, 5, 495-500.

https://doi.org/10.1016/S0031-8914(38)80162-2

[27] Kittel, C. (1972) Introduction à la Physique de l'état Solide. 284-285.

[28] Fatimata, B.A., Seibou, B., Wade, M., Diouf, M.S., Ly, I. and Sissoko, G. (2016) International Journal of Electronics \& Communication, 4, 1-11.

[29] El Hadji, N., Sahin, G., Thiam, A., Dieng, M., Diallo, H.L., Ndiaye, M. and Sissoko, G. (2015) Journal of Applied Mathematics and Physics, 3, 1522-1535. https://doi.org/10.4236/jamp.2015.311177 